\title{
The Russian National Standard of Gases Humidity and Traceability System of Humidity Measurements
}

\author{
N. I. Dubovikov ${ }^{1}$ - O. A. Podmurnaya ${ }^{1}$. \\ N. P. Skryabikov ${ }^{1}$ - I. A. Sokov ${ }^{1}$ - A. F. Vinge ${ }^{1}$
}

Received: 3 October 2010 / Accepted: 11 October 2015 / Published online: 11 March 2016

C The Author(s) 2016. This article is published with open access at Springerlink.com

\begin{abstract}
The Russian national humidity standard of gases has been modernized in order to increase the number of reproducible quantities of humidity (relative humidity, dew/frost-point temperature, mole fraction) and to extend the humidity and operating temperature ranges. The basis of the standard comprises two humidity generators with operating temperature ranges from $5^{\circ} \mathrm{C}$ to $90^{\circ} \mathrm{C}$ and from $-60^{\circ} \mathrm{C}$ to $15^{\circ} \mathrm{C}$. The common working range (from $5^{\circ} \mathrm{C}$ to $15^{\circ} \mathrm{C}$ ) allows comparison of the generators. The generators use the two-pressure method to generate humid gas defined in terms of the relative humidity (from $5 \%$ rh to $98 \%$ rh at temperatures from $90^{\circ} \mathrm{C}$ to $-60^{\circ} \mathrm{C}$ ) and the one-pressure (or phase equilibrium) method to generate humid gas defined in terms of the vapor mole fraction (from $0.6 \mathrm{ppm}$ to $700 \times 10^{3} \mathrm{ppm}$ ) and dew/frostpoint temperature (from $-79^{\circ} \mathrm{C}$ to $90^{\circ} \mathrm{C}$ ). The expanded uncertainty in the relative humidity is no more than $0.2 \% \mathrm{rh}$, no more than $1.2 \%$ in the vapor mole fraction, and no more than $0.12^{\circ} \mathrm{C}$ in the dew/frost-point temperature. The ordinary hygrometers are traceable to the national primary standard in accordance with the state hierarchical chain for measuring means of gas humidity. The state hierarchical chain consists of three branches for means of measurements: (a) mole fraction, (b) dew/frost-point temperature, and (c) relative humidity with each branch represented as the scheme: primary standard-secondary standard-working standard-ordinary hygrometer. Calibration and verification of working standards and ordinary hygrometers, and their traceability to the primary standard use methods of (i) direct measurements, (ii) direct comparison, or (iii) comparison with a comparator.
\end{abstract}

Keywords Gas humidity $\cdot$ Hierarchical chain $\cdot$ Humidity standard · Traceability

$凶$ O. A. Podmurnaya dep15@niiftri.irk.ru

1 All-Russian Scientific Research Institute of Physico-Technical Measurements (VNIIFTRI) East-Siberian Branch, Irkutsk, Russian Federation 


\section{Introduction}

According to the State Register, about 120 types of hygrometers, humidity analyzers, and transducers and 15 types of humidity generators are operated in the territory of Russia and an estimated 1.5 million to 3 million units are used. About 50 local hierarchical chains for measuring humidity were formed during the period in which metrological assurance in hygrometry was decentralized, i.e., before 1986 .

The development of the national primary standard of relative humidity and certification in 1986 was the first step to establish the national traceability system in hygrometry. In 2006, three reproducible quantities of humidity were selected to be supported by the state-relative humidity, dew/frost-point temperature, and vapor mole fraction-and the dew-point temperature and operating temperature ranges were to be extended upward to $90^{\circ} \mathrm{C}$. Consequently, a modernized standard and national hierarchical chain are now the basis of the national traceability system in hygrometry. In Sect. 2, an overview of the Russian national humidity standard is presented. The realization of the vapor mole fraction, dew/frost-point temperature, and relative humidity is presented in Sect. 3, and an uncertainty analysis is developed and presented in Sect. 4. Finally, traceability to the SI via the All-Russian Scientific Research Institute of Physico-Technical Measurements (VNIIFTRI) and vapor-pressure reference equations are discussed in Sect. 5.

\section{National Standard of Gas Humidity}

According to the State Register of the Russian national standards, the Russian national primary standard of gas humidity is assigned a number GET 151-2010 (GET 151) and reproduces the three most requested quantities of humidity: mole fraction, dew/frostpoint temperature, and relative humidity.

The national primary standard reproduces and transfers

1. mole fraction $x_{n}$ from $0.6 \mathrm{ppm}$ to $700 \times 10^{3} \mathrm{ppm}$ with a standard uncertainty for a type A evaluation $u_{\mathrm{A}}$ which does not exceed $0.3 \%$ and a standard uncertainty for a type $\mathrm{B}$ evaluation $u_{\mathrm{B}}$ which does not exceed $0.58 \%$;

2. dew/frost-point temperature $t_{\mathrm{d}}$ from $-79^{\circ} \mathrm{C}$ to $+90^{\circ} \mathrm{C}$ with a standard uncertainty for a type A evaluation $u_{\mathrm{A}}$ which does not exceed $0.05^{\circ} \mathrm{C}$ and a standard uncertainty for type $\mathrm{B}$ evaluation $u_{\mathrm{B}}$ which does not exceed $0.03^{\circ} \mathrm{C}$;

3. relative humidity from $5 \%$ rh to $98 \%$ rh (at temperatures from $90^{\circ} \mathrm{C}$ to $-60{ }^{\circ} \mathrm{C}$ ) with a standard uncertainty for a type A evaluation $u_{\mathrm{A}}$ which does not exceed 0.05 $\%$ and a standard uncertainty for a type B evaluation $u_{\mathrm{B}}$ which does not exceed $0.04 \%$ at positive temperatures and $0.08 \%$ at negative temperatures

\subsection{Overview}

The national primary standard comprises the following:

- two standard humidity generators operating within the temperatures ranges of $-60{ }^{\circ} \mathrm{C}$ to $+15^{\circ} \mathrm{C}$ and $+5{ }^{\circ} \mathrm{C}$ to $+90^{\circ} \mathrm{C}$, 


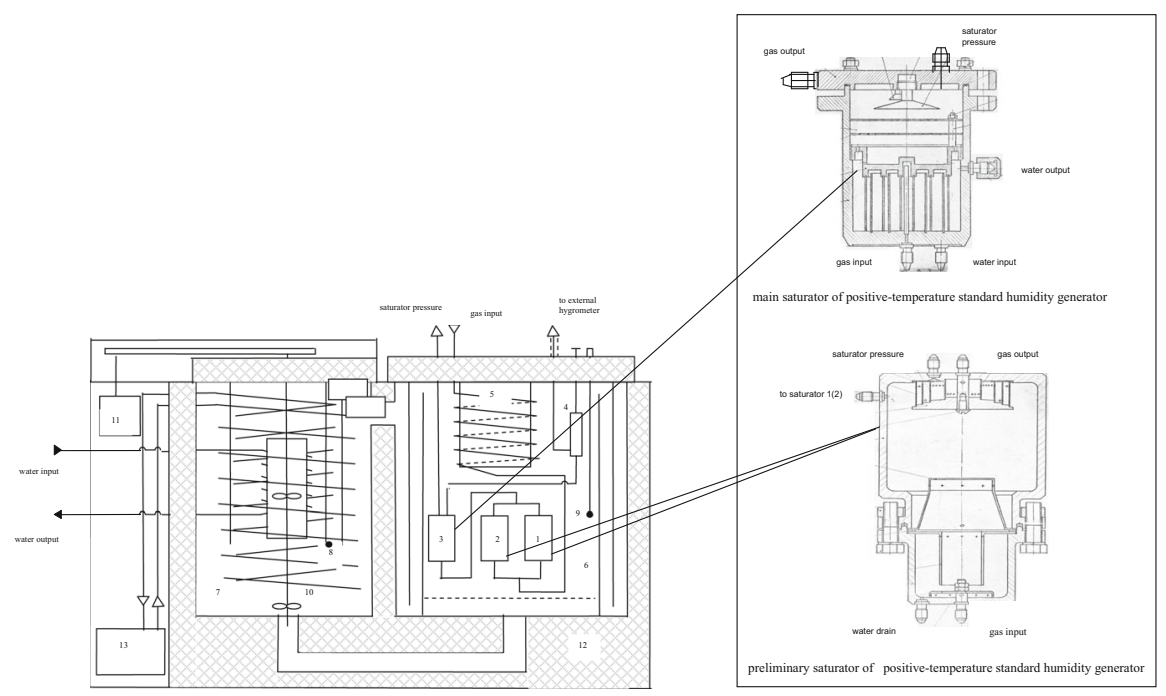

Fig. 1 Schematic diagram of positive-temperature humidity generator. 1, 2 presaturator, 3 main saturator, 4 throttle, 5 working chamber, 6 working volume, 7 preliminary volume, 8 thermoregulator, 9 measuring thermometer, 10 mixer, 11 mixer motor, 12 thermostat, 13 refrigerator

- dry gas generator;

- gas conditioning equipment;

- precision hygrometer kit for stability control of standard humidity generators; and

- measuring and computing complex.

The national primary standard reproduces units of gas humidity within the temperature range from $-60^{\circ} \mathrm{C}$ to $+90^{\circ} \mathrm{C}$. The common working range from $+5^{\circ} \mathrm{C}$ to $+15^{\circ} \mathrm{C}$ allows comparison of the generators. Standard generators which are parts of the standard are compared periodically during operation of the standard. Each generator reproduces the same several values of humidity (commonly, 2 to 3 ) measured by check hygrometers interchangeably. Reproducibility of measurements of both generators does not exceed the systematic component of the standard uncertainty.

The basic components of the standard are humidity generators. A schematic diagram of the humidity generator at positive temperatures is shown in Fig. 1. Compressed gas is fed to the generator input through the pressure reducer which is used to control the absolute pressure of the gas at a setting in the range of $0.1 \mathrm{MPa}$ to $2 \mathrm{MPa}$ as it passes through the heat exchanger and saturator system 1-3. After saturation, the humid gas pressure is reduced by using the isothermal throttle 4 . Water vapor can be condensed in the throttle because of a decrease in temperature as a result of the JouleThomson effect [1] so that the humidity of the gas is lower than that in the saturator. To minimize this effect, a specially designed isothermal throttle with a long length needle cone for a more modulated decrease of pressure (and temperature, respectively) is used. The case construction of the needle improves heat transfer between the needle and the thermostating liquid and compensates the decrease of temperature caused by 


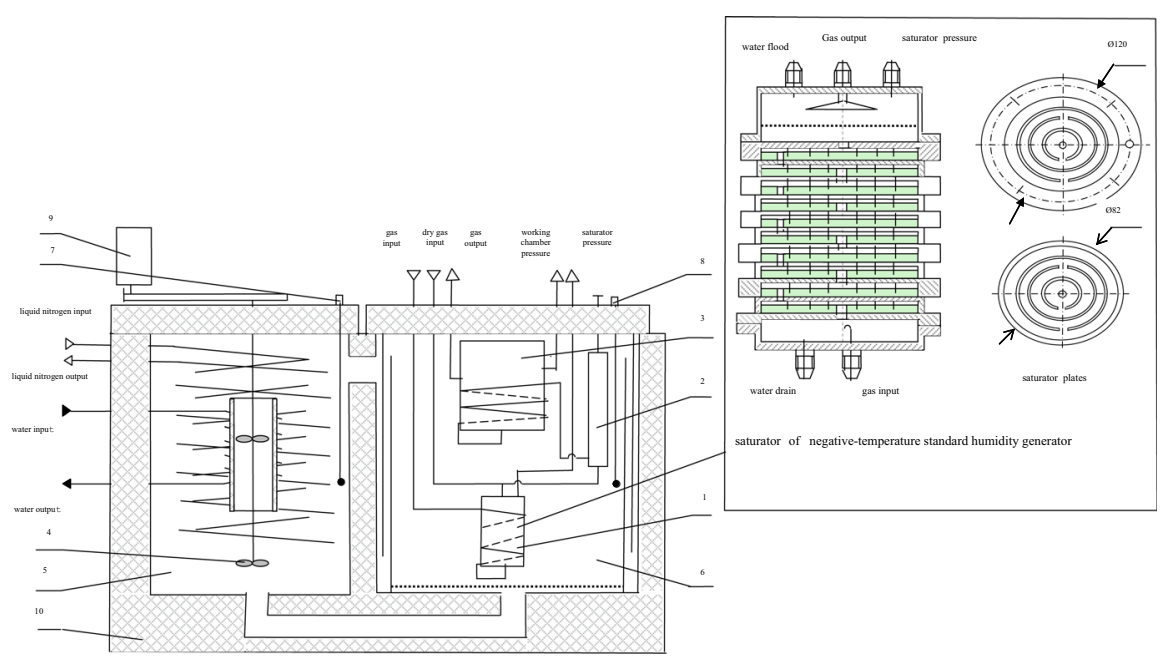

Fig. 2 Schematic diagram of negative-temperature standard generator. 1 saturator, 2 throttle, 3 working chamber, 4 mixer, 5 preliminary volume, 6 working volume, 7 thermoregulator, 8 measuring thermometer, 9 mixer motor, 10 thermostat

the throttling effect. Investigations using a specially designed 10 cleavage copperconstantan thermocouple showed that the residual cooling effect was negligible.

After passing through the throttle, humid gas can be fed to the working chamber 5 or the external hygrometer. The gas passes to the atmosphere from the working chamber through the flowmeter. The saturator, throttle, and working chamber are contained in the liquid bath, the temperature of which is set and maintained by the thermostatic system. In the "positive-temperature" (i.e., for $t>0{ }^{\circ} \mathrm{C}$ ) standard generator, water is used as the operated thermostatic liquid; the electric heaters are used for heating. If the saturation temperature is more than $+15^{\circ} \mathrm{C}$, flowing water is used for cooling. If the saturation temperature is less than $+15^{\circ} \mathrm{C}$, a compressor (refrigerating machine) is used for cooling.

The saturation system of the positive-temperature standard generator has two stages. The first stage of presaturation comprises two in-parallel saturators 1, 2. Gas passes through the heat exchanger connecting the presaturator and the main saturator 3 . Barborators-saturators in which gas bubbles through water columns $0.2 \mathrm{~m}$ long divided by three steps - are used in the positive-temperature standard generator.

The negative-temperature standard generator uses gas dried in the dry gas generator to prevent freezing of tubes. Alcohol is used as the operating thermostatic liquid, with liquid nitrogen providing the cooling. The saturation system of the negativetemperature standard generator (Fig. 2) comprises the saturator which consists of a sequence of connected plates, $82 \mathrm{~mm}$ and $120 \mathrm{~mm}$ in diameter, which provides effective heat exchange and compensation of a temperature decrease in the process of saturation. The saturator plates contain axial-type guides about their center. The path length of the ice or water surface in the saturator is $2.4 \mathrm{~m}$. An excess pressure of gas in the saturators and working chambers is measured by the IPD-manometers. Atmospheric pressure is measured by the M 75-2-microbarograph. The temperature in the thermostats of 
the standard generators is measured by TSPN-5V- or PTSV-2K-1-platinum resistance thermometers.

\section{Realization of Humidity Units}

\subsection{Realization of Mole Fraction}

In accordance with RIS 75-2004, "The State System for Ensuring Uniform Measurement of Substances Moisture and Humidity. Terms and Definitions" [2], the vapor mole fraction $x_{n}$ is defined as the ratio of the substance amount of water vapor in the gas $n_{\mathrm{v}}$ to the total substance amount of the moist gas $n$,

$$
x_{n}=\frac{n_{\mathrm{v}}}{n} .
$$

As realized by standard generators GET $151, x_{n}$ is defined by

$$
x_{n}=\frac{e\left(t_{\mathrm{s}}\right) \cdot f\left(P_{\mathrm{s}}, t_{\mathrm{s}}\right)}{P_{\mathrm{s}}} .
$$

Here $t_{\mathrm{s}}$ is the saturation temperature and $P_{\mathrm{s}}$ is the absolute pressure in the saturator, $e\left(t_{\mathrm{S}}\right)$ is the saturated vapor pressure at $t_{\mathrm{S}}$ and $f\left(P_{\mathrm{s}}, t_{\mathrm{s}}\right)$ is the water-vapor enhancement factor evaluated at $t_{\mathrm{s}}$ and

$$
P_{\mathrm{s}}=P_{\mathrm{ds}}+P_{\mathrm{a}}
$$

where $P_{\mathrm{a}}$ is the atmospheric pressure and $P_{\mathrm{ds}}$ is the gauge pressure in the saturator.

\subsection{Realization of Dew/Frost-Point Temperature}

In accordance with [2], the dew/frost-point temperature $t_{\mathrm{d}}$ is the temperature at which water vapor in gas is cooled isobarically (e.g., at the pressure $P_{\mathrm{c}}$ ) is being saturated above the water (ice).

The dew/frost-point temperature of moist gas $t_{\mathrm{d}}$ will be approximately equal to the saturation temperature $t_{\mathrm{s}}$ when the pressure in the working chamber/external hygrometer $P_{\mathrm{c}}$ is approximately equal to the pressure in the saturator $P_{\mathrm{s}}$. But when the pressure in the working chamber/external hygrometer $P_{\mathrm{c}} \neq P_{\mathrm{s}}, t_{\mathrm{d}}$ must be calculated by the method of sequential approximations (at the starting value $f\left(P_{\mathrm{c}}, t_{\mathrm{d}}\right)=1$ ) from the equation,

$$
e\left(t_{\mathrm{d}}\right) \cdot f\left(P_{\mathrm{c}}, t_{\mathrm{d}}\right)=x_{n}\left(P_{\mathrm{s}}, t_{\mathrm{s}}\right) \cdot P_{\mathrm{c}}
$$

where $e\left(t_{\mathrm{d}}\right)$ is the saturation pressure of saturated water vapor at the temperature $t_{\mathrm{d}}, f\left(P_{\mathrm{c}}, t_{\mathrm{d}}\right)$ is the water-vapor enhancement factor evaluated at $P_{\mathrm{c}}$, and $t_{\mathrm{d}}, x_{n}\left(P_{\mathrm{s}}, t_{\mathrm{s}}\right)$ is the mole fraction in gas at temperature $t_{\mathrm{s}}$ and pressure $P_{\mathrm{s}}$ in the process of saturation and 


$$
P_{\mathrm{c}}=P_{\mathrm{dc}}+P_{\mathrm{a}}
$$

where $P_{\mathrm{dc}}$ is the gauge pressure in the chamber

\subsection{Realization of Relative Humidity}

In choosing standard instruments of gas relative humidity, preference should be given to a generator based on the two-pressure method, which is considered to be the absolute and the most accurate method of reproduction of a relative humidity scale [3]. The principle of this method is that gas saturated with water vapor at an elevated pressure is then isothermally throttled to the pressure of the working chamber or test hygrometers. In this case, the saturator temperature and the working chamber temperature are equal. In accordance with [2], the relative humidity above water (ice) $h$ is the ratio of the mole fraction in the gas to the mole fraction of saturated water vapor above water (ice) in this gas at the same temperature and pressure. Therefore, using the two-pressure method, the relative humidity is defined by

$$
h=\left(\frac{x_{n}}{x_{n \mathrm{~s}}}\right)_{P_{\mathrm{c}}, t_{\mathrm{c}}}=\frac{x_{n}\left(P_{\mathrm{s}}, t_{\mathrm{s}}\right)}{x_{n}\left(P_{\mathrm{c}}, t_{\mathrm{c}}\right)}=\frac{P_{\mathrm{c}} \cdot e\left(t_{\mathrm{s}}\right) \cdot f\left(P_{\mathrm{s}}, t_{\mathrm{s}}\right)}{P_{\mathrm{s}} \cdot e\left(t_{\mathrm{c}}\right) \cdot f\left(P_{\mathrm{c}}, t_{\mathrm{c}}\right)} \cong \frac{P_{\mathrm{c}} \cdot f\left(P_{\mathrm{s}}, t_{\mathrm{s}}\right)}{P_{\mathrm{s}} \cdot f\left(P_{\mathrm{c}}, t_{\mathrm{s}}\right)},
$$

where $f\left(P_{\mathrm{c}}, t_{\mathrm{s}}\right)$ is the enhancement factor of moist gas evaluated at $\left(P_{\mathrm{c}}, t_{\mathrm{s}}\right)$, and $x_{n}$ is given by Eq. 2 and $x_{n \mathrm{~s}}$ is the mole fraction of the gas if saturated at $t_{\mathrm{c}}$ and $P_{\mathrm{c}}$.

\section{Uncertainty Analysis}

Uncertainties in the quantities are expressed using the notation such that $u\left(P_{\mathrm{c}}\right)$ denotes the standard uncertainty in quantity $P_{\mathrm{c}}$. Relative standard uncertainties are denoted with an additional subscript ' $\mathrm{r}$ ' as in $u_{\mathrm{r}}(x)$.

The uncertainty of gas humidity units generated by the GET 151 is dictated by the following uncertainties.

The uncertainty of the pressure measurement is determined by uncertainties of the pressure transducer and a monitor such as the multirange metric pressure transducer (IPD) used to measure the gauge pressure $P_{\mathrm{ds}}$ in the saturator and $P_{\mathrm{dc}}$ in the working chamber.

The uncertainty of the IPD is no more than $0.06 \%$. An Agilent data collector (multimeter) monitors the IPD with a relative uncertainty of no more than $0.005 \%$. Several transducers closed off the full-range pressure in the saturator and the working chamber was used for the measurement of pressure with relative uncertainties less than $0.1 \%$.

The uncertainty in temperature is derived from the temperature instability and inhomogeneity, the temperature transducer, the monitor, and the selected method of the temperature measurement. The transducers are VNIIFTRI traceable platinum resistance thermometers (PRTs) having uncertainties between $0.005^{\circ} \mathrm{C}$ and $0.01^{\circ} \mathrm{C}$.

The uncertainty in temperature due to the voltage measurement corresponding to the temperature range from $-60{ }^{\circ} \mathrm{C}$ to $+90^{\circ} \mathrm{C}$ is not more than $0.01{ }^{\circ} \mathrm{C}$ when 
Table 1 Uncertainty (relative) budget for mole fraction

\begin{tabular}{|c|c|c|c|c|}
\hline \multirow[t]{4}{*}{ Source of uncertainty } & \multicolumn{4}{|c|}{$\begin{array}{l}\text { Uncertainty contribution } u_{i}(\%) \\
\text { Working temperature }\left({ }^{\circ} \mathrm{C}\right)\end{array}$} \\
\hline & \multicolumn{2}{|l|}{-60} & \multicolumn{2}{|l|}{+90} \\
\hline & \multicolumn{4}{|c|}{ Mole fraction (ppm) } \\
\hline & 0.6 & 10 & $40 \times 10^{3}$ & $700 \times 10^{3}$ \\
\hline Temperature & 0.2 & 0.2 & 0.1 & 0.1 \\
\hline Pressure in saturator & 0.07 & 0.07 & 0.07 & 0.07 \\
\hline Enhancement-factor formula & 0.4 & 0.003 & 0.06 & 0.003 \\
\hline Saturation vapor pressure formula & 0.2 & 0.2 & 0.1 & 0.1 \\
\hline Type B uncertainty (relative) & 0.5 & 0.3 & 0.17 & 0.16 \\
\hline Type A uncertainty & 0.3 & 0.3 & 0.3 & 0.3 \\
\hline Combined standard uncertainty $(k=1)$ & 0.58 & 0.43 & 0.35 & 0.34 \\
\hline Expanded uncertainty $(k=2)$ & 1.2 & 0.84 & 0.68 & 0.67 \\
\hline
\end{tabular}

measuring with the Agilent or $0.001{ }^{\circ} \mathrm{C}$ when measuring with the MIT 8.15. The twochamber thermostats TVP-6 refined for the purpose of minimizing thermal interchange with the environment and decreasing nonuniformity of the temperature field in the working volume and gradient between the saturator and working chamber to $0.006^{\circ} \mathrm{C}$ at a temperature instability of no more than $0.003^{\circ} \mathrm{C}$ are used for thermostatting the saturator and working chamber. Therefore, the combined temperature uncertainty (no more than $(0.01 \ldots 0.02){ }^{\circ} \mathrm{C}$ ) leads to the temperature component uncertainty of saturated water-vapor pressure $u\left(e_{\mathrm{t}}\right)$ which is no more than $0.28 \%$. The uncertainty of the saturated water-vapor pressure formulae $u\left(e_{\mathrm{f}}\right)$ within these temperature limits is changed from $0.01 \%$ to $0.22 \%$ [4].

Deviation of the moist gas from the ideal gas is taken into account by enhancement factors $f\left(P_{\mathrm{c}}, t_{\mathrm{s}}\right)$ and $f\left(P_{\mathrm{s}}, t_{\mathrm{s}}\right)$. Within the analyzed range of the working GET 151 standards, the relative uncertainty of the reference data on enhancement factors of moist nitrogen (air) [5-8] is no more than $1.4 \%$.

Recent experimental research ([9] involving the evaluation of the difference of the dew/frost-point reproduced by GET 151 and measured by an external precision hygrometer, the moist gas flow changes of hopping from minimum to maximum values confirms the findings of theoretical calculations and earlier experimental studies [10] that the uncertainty associated with oversaturation/undersaturation (sometimes called saturator efficiency) is an order of magnitude less than other uncertainty components.

Uncertainty budgets for the mole fraction, dew/frost-point temperature, and relative humidity are developed below and represented by Tables 1,2, and 3, respectively.

\subsection{Uncertainty Analysis for Mole Fraction}

In accordance with Eq. 2, the relative uncertainty of the mole fraction $u_{\mathrm{r}}\left(x_{n}\right)$ is defined by 
Table 2 Uncertainty budget for dew/frost-point temperature

\begin{tabular}{|c|c|c|}
\hline \multirow[t]{2}{*}{ Source of uncertainty } & \multicolumn{2}{|c|}{$\begin{array}{l}\text { Uncertainty contribution } u_{i}\left({ }^{\circ} \mathrm{C}\right) \\
\text { Dew/frost-point temperature }\left({ }^{\circ} \mathrm{C}\right)\end{array}$} \\
\hline & -79 & +90 \\
\hline Temperature & 0.0024 & 0.00173 \\
\hline Pressure in saturator & 0.006 & 0.0009 \\
\hline Pressure in working chamber & 0.00023 & 0.0009 \\
\hline Saturation vapor pressure formula (saturator) & 0.0177 & 0.00076 \\
\hline $\begin{array}{l}\text { Saturation vapor pressure formula (working } \\
\text { chamber) }\end{array}$ & 0.0177 & 0.00076 \\
\hline Enhancement-factor formulae (saturator) & 0.0141 & 0.00076 \\
\hline $\begin{array}{l}\text { Enhancement-factor formulae } \\
\text { (working chamber) }\end{array}$ & 0.0141 & 0.00076 \\
\hline $\begin{array}{l}\text { Type B uncertainty for dew/frost-point } \\
\text { temperature }\end{array}$ & 0.0326 & 0.0026 \\
\hline $\begin{array}{l}\text { Type A uncertainty for dew/frost-point } \\
\text { temperature }\end{array}$ & 0.05 & 0.05 \\
\hline $\begin{array}{l}\text { Combined uncertainty for dew/frost-point } \\
\text { temperature }(k=1)\end{array}$ & 0.06 & 0.058 \\
\hline $\begin{array}{l}\text { Expanded uncertainty for dew/frost-point } \\
\text { temperature }(k=2)\end{array}$ & 0.12 & 0.11 \\
\hline
\end{tabular}

Table 3 Uncertainty budget for relative humidity

\begin{tabular}{|c|c|c|c|c|}
\hline \multirow[t]{3}{*}{ Source of uncertainty } & \multicolumn{4}{|c|}{$\begin{array}{l}\text { Uncertainty contribution } u_{i}(\% \mathrm{rh}) \\
\text { Working temperature }\left({ }^{\circ} \mathrm{C}\right)\end{array}$} \\
\hline & \multicolumn{2}{|l|}{-60} & \multicolumn{2}{|l|}{+90} \\
\hline & $h=5 \% \mathrm{rh}$ & $h=98 \% \mathrm{rh}$ & $h=5 \% \mathrm{rh}$ & $h=98 \% \mathrm{rh}$ \\
\hline Temperature & 0.01 & 0.06 & 0.003 & 0.05 \\
\hline Pressure measurement & 0.01 & 0.03 & 0.006 & 0.03 \\
\hline Enhancement-factor formulae & 0.02 & 0.00 & 0.003 & 0.001 \\
\hline Type B uncertainty (absolute) & 0.03 & 0.06 & 0.007 & 0.06 \\
\hline Type A uncertainty & 0.05 & 0.05 & 0.05 & 0.05 \\
\hline Combined uncertainty $(k=1)$ & 0.06 & 0.08 & 0.05 & 0.08 \\
\hline Expanded uncertainty $(k=2)$ & 0.12 & 0.16 & 0.12 & 0.15 \\
\hline
\end{tabular}

$$
u_{\mathrm{r}}\left(x_{n}\right)=\sqrt{u_{\mathrm{r}}\left(P_{\mathrm{s}}\right)^{2}+u_{\mathrm{r}}\left(e_{\mathrm{t}}\right)^{2}+u_{\mathrm{r}}\left(e_{\mathrm{f}}\right)^{2}+u_{\mathrm{r}}\left(f\left(P_{\mathrm{s}}, t_{\mathrm{s}}\right)\right)^{2}},
$$

where

$$
u\left(P_{\mathrm{s}}\right)=\sqrt{\left(u\left(P_{\mathrm{a}}\right) \cdot \frac{P_{\mathrm{a}}}{\left(P_{\mathrm{a}}+P_{\mathrm{ds}}\right)}\right)^{2}+\left(u_{\mathrm{r}}\left(P_{\mathrm{ds}}\right) \frac{P_{\mathrm{ds}}}{\left(P_{\mathrm{a}}+P_{\mathrm{ds}}\right)}\right)^{2}}
$$


$u_{\mathrm{r}}\left(e_{\mathrm{t}}\right)$ is the uncertainty of temperature measurement and temperature instability and nonuniformity; $u_{\mathrm{r}}\left(e_{\mathrm{f}}\right)$ is the uncertainty of the saturated water-vapor pressure formulae [4]; $u\left(f\left(P_{\mathrm{s}}, t_{\mathrm{s}}\right)\right)$ is the uncertainty of enhancement factors [5-8], and $u\left(P_{\mathrm{a}}\right)$ and $u\left(P_{\mathrm{ds}}\right)$ are uncertainties of the atmospheric-pressure measurement and the pressure measurement in the saturator.

The limits of uncertainty (relative) for the mole fraction $u_{\mathrm{B}}\left(x_{n}\right)$ calculated from given methods are reported in the uncertainty budget in Table 1.

\subsection{Uncertainty Analysis for Dew/Frost-Point Temperature}

Sources of uncertainty in the dew/frost-point temperature measurement include those given for vapor mole fraction and, in addition, those associated with the measurement of pressure in the chamber or at the hygrometer. In accordance with the definition (Eq. 4) and taking into account correlation in components of uncertainty type B, the uncertainty of the dew/frost-point temperature $-u\left(t_{\mathrm{d}}\right)$ at the pressure $P_{\mathrm{c}}$ (not equal to the saturation pressure $P_{\mathrm{s}}$ ) is defined by

$$
\begin{aligned}
& u\left(e_{\mathrm{d}}\right)=\sqrt{u\left(P_{\mathrm{c}}\right)^{2}+u\left(P_{\mathrm{s}}\right)^{2}+u\left(e_{\mathrm{t}}\right)^{2}+u\left(e_{\mathrm{f}}\right)^{2}+u\left(f\left(P_{\mathrm{s}}, t_{\mathrm{s}}\right)\right)^{2}}, \\
& u\left(t_{\mathrm{d}}\right)=t_{\mathrm{d}}\left(e_{\mathrm{d}}\right)-t_{\mathrm{d}}\left(e_{\mathrm{d}}+u\left(e_{\mathrm{d}}\right)\right),
\end{aligned}
$$

where $u\left(P_{\mathrm{S}}\right)$ and $u\left(P_{\mathrm{c}}\right)$ are uncertainties of the pressure measurement in the saturator and working chamber (external hygrometer) in accordance with Eq. $8 ; u\left(e_{\mathrm{t}}\right)$ is the uncertainty of the temperature measurement in accordance with

$$
u\left(e_{\mathrm{t}}\right)=h \cdot \frac{1}{e(t)} \frac{\partial e}{\partial t} u(t)
$$

and the temperature instability and nonuniformity; $u\left(e_{\mathrm{f}}\right)$ is the uncertainty of the saturated water-vapor pressure formulae [4]; and $u\left(f\left(P_{\mathrm{S}}, t_{\mathrm{S}}\right)\right)$ is the uncertainty of enhancement factors [5-8]. The uncertainty budget for the dew/frost-point temperature is listed in Table 2.

\subsection{Uncertainty Analysis for Relative Humidity}

Sources of uncertainty in the relative humidity include those given for the dew/frostpoint temperature and, in addition, those associated with the measurement of temperature in the chamber or at the hygrometer. In accordance with Eq. 6 and correlation relationships in uncertainty pairs $u\left(P_{\mathrm{c}}\right), u\left(P_{\mathrm{s}}\right), u\left(f\left(P_{\mathrm{s}}, t_{\mathrm{s}}\right)\right)$, and $u\left(f\left(P_{\mathrm{c}}, t_{\mathrm{s}}\right)\right.$, the (absolute) uncertainty of the relative humidity is defined by the following formula for the residual bias limit:

$$
u(h)=\sqrt{u(h)_{\mathrm{P}}^{2}+u(e)_{\mathrm{t}}^{2}+u(f)^{2}},
$$


where

$$
\begin{aligned}
& u(h)_{\mathrm{P}} \\
& =h \cdot \sqrt{\left(u_{\mathrm{r}}\left(P_{\mathrm{a}}\right) \frac{P_{\mathrm{a}}\left(P_{\mathrm{ds}}-P_{\mathrm{dc}}\right)}{\left(P_{\mathrm{a}}+P_{\mathrm{ds}}\right)\left(P_{\mathrm{a}}+P_{\mathrm{dc}}\right)}\right)^{2}+\left(u_{\mathrm{r}}\left(P_{\mathrm{dc}}\right) \frac{P_{\mathrm{dc}}}{\left(P_{\mathrm{a}}+P_{\mathrm{dc}}\right)}\right)^{2}+\left(u_{\mathrm{r}}\left(P_{\mathrm{ds}}\right) \frac{P_{\mathrm{ds}}}{\left(P_{\mathrm{a}}+P_{\mathrm{ds}}\right)}\right)^{2}}, \\
& u(f)=h \cdot \sqrt{u_{\mathrm{r}}\left(f\left(P_{\mathrm{s}}, t_{\mathrm{s}}\right)\right)^{2}+u_{\mathrm{r}}\left(f\left(P_{\mathrm{c},}, t_{\mathrm{s}}\right)\right)^{2}} .
\end{aligned}
$$

Limits of (absolute) uncertainty for the relative humidity are given in the uncertainty budget listed in Table 3 .

\section{Traceability System}

The metrological traceability chain of gas humidity measurements was established after introduction of the GET 151-86 [10], the national standard of gas relative humidity. The traceability of relative humidity hygrometers to the national standard was realized in accordance with the hierarchical chain [11]. Changes in aims of the measurement, a fleet of the measuring means used in Russia which took place since 1986, have required the modernization of the standard and updating of the traceability system. The standard and metrological traceability chain was modernized in 2006-2009. At the present time, traceability is transferred from the national standards to working instruments in accordance with the Russian regulatory and legal framework in hygrometry [2] and the hierarchical chain [12].

The state hierarchical chain consists of three branches: for measuring the mole fraction, dew/frost-point temperature, and relative humidity, respectively. Each branch can be represented as the scheme: primary standard-secondary standard-working standard-ordinary hygrometer. The branch of the hierarchical chain just for measuring the dew/frost-point temperature is shown in Fig. 3.

Humidity generators that produce a gas mixture with defined moisture are mostly used as class-1 and class-2 working generators (e.g., "Rodnik-2," "Rodnik3," and "Rodnik-6" generators.) Meteorological humidity transducers, hygrometers, and hygrographs are usually calibrated in climatic chambers using calibrated highaccuracy hygrometers (including generators) as class-2 working standards (e.g., "KONG-Prima 4," "KONG-Prima 1," "Michell Instruments S 4000," and "MBW 373 Dew-Point Mirror" hygrometer).

Because secondary and class-1 working standards are generators, it is natural to compare these standards with the primary standard by using the hygrometer as a traveling measurement standard. The method of direct measurements is used for calibration of class- 2 working standard-hygrometers, the method of comparison with a comparator-for calibration of class- 2 working standards-humid gas generator, and methods of direct measurements and direct comparison are used for calibration of working hygrometers.

Piezosorption, resistive, capacitance-type relative humidity, coulometric-type mole fraction, and condensation-type dew/frost-point hygrometers are used as the traveling standard. 


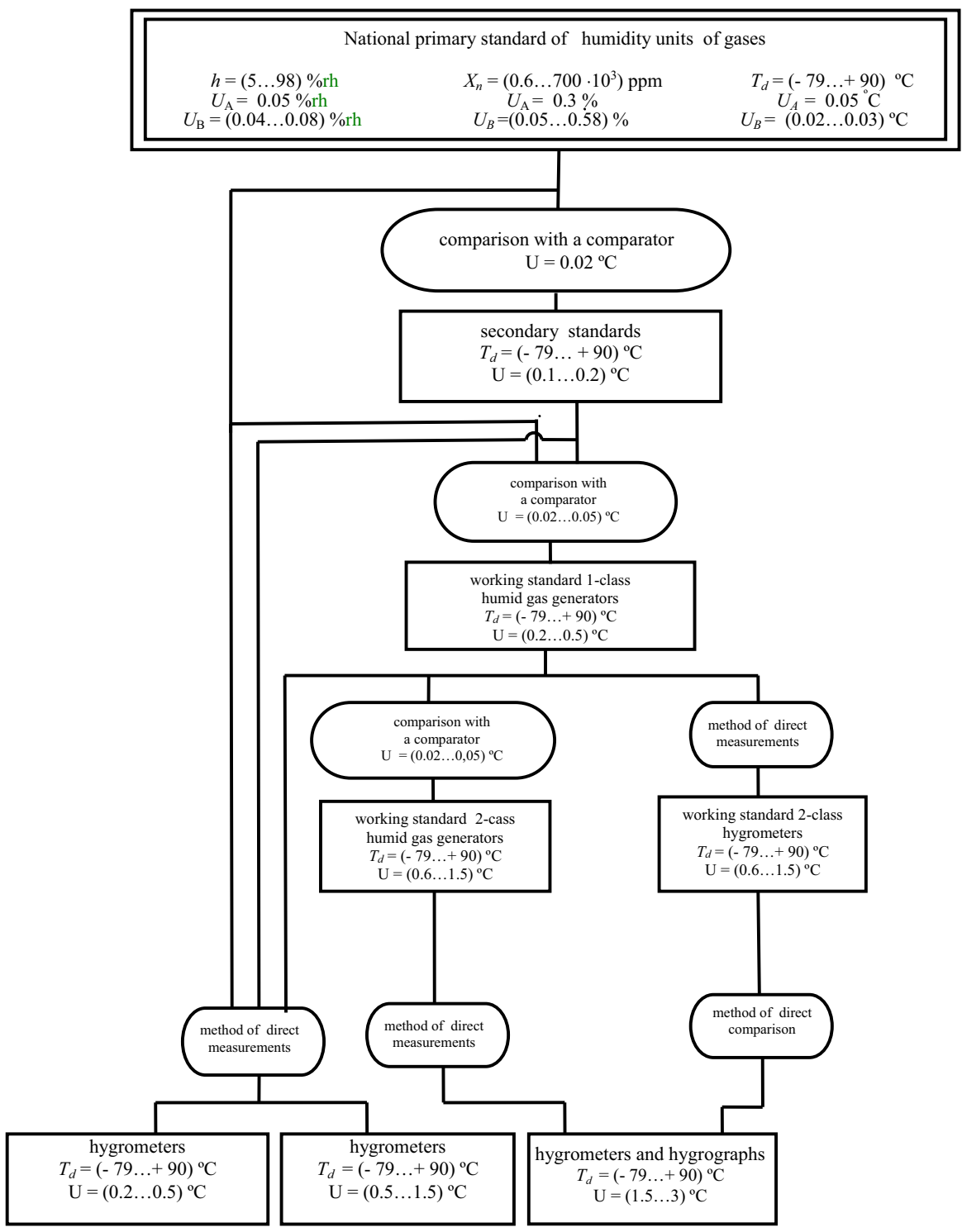

Fig. 3 State hierarchical chain for measuring means of dew/frost point

\section{Conclusion}

The GET 151 standard of gas humidity was modernized in VNIIFTRI. The operating temperature now extends from $-60^{\circ} \mathrm{C}$ to $+90^{\circ} \mathrm{C}$. The basis of the primary standard is a positive-temperature generator (with a working range from $+5^{\circ} \mathrm{C}$ to $+90^{\circ} \mathrm{C}$ ) and a negative-temperature generator (from $-60^{\circ} \mathrm{C}$ to $+15^{\circ} \mathrm{C}$ ), thus enabling comparisons over the range from $5^{\circ} \mathrm{C}$ to $15^{\circ} \mathrm{C}$. 
The phase equilibrium method (one-pressure method) is used to generate humid gas defined in terms of the vapor mole fraction $\left(0.6 \mu \mathrm{mol} \cdot \mathrm{mol}^{-1}\right.$ to $0.7 \mathrm{~mol} \cdot \mathrm{mol}^{-1}$ with maximum relative expanded uncertainties of $1.2 \%$ ). Two-pressure generators reproduce humid gas defined in terms of the relative humidity (from $5 \%$ rh to $98 \% \mathrm{rh}$, with maximum expanded uncertainties of $0.2 \% \mathrm{rh}$ ), and the dew/frost-point temperature from $-79^{\circ} \mathrm{C}$ to $+90^{\circ} \mathrm{C}$ with maximum expanded uncertainties in dew/frost-point temperature of $0.12{ }^{\circ} \mathrm{C}$.

A modernized standard and redeveloped national hierarchical chain for measuring means of gas humidity are the basis of the national traceability system in hygrometry providing the traceability of working standards and instruments to the national standard of gas humidity.

Acknowledgments The authors express their sincere thanks to the editor for helpful advice.

Open Access This article is distributed under the terms of the Creative Commons Attribution 4.0 International License (http://creativecommons.org/licenses/by/4.0/), which permits unrestricted use, distribution, and reproduction in any medium, provided you give appropriate credit to the original author(s) and the source, provide a link to the Creative Commons license, and indicate if changes were made.

\section{References}

1. Physical Encyclopaedia (Soviet Encyclopaedia, Moscow, 1988), p. 605

2. RIS 75-2004 State System for Ensuring Uniform Measurement of Substances Moisture and Humidity. Terms and Definitions (Isdatelstvo standartov, Moskow, 2004), pp. 1-18

3. N.N. Dubovikov, A.P. Dozorcev, O.A. Podmurnaya, M.B. Fridzon, Izmeritelnaya Technica 3, 33 (1986)

4. D. Sonntag, Zeitschrift für Meteorologie 40, 340 (1990)

5. M.B. Iomtev, V.G. Piskunov, V.L. Kadjaev, Tables of Recommended Reference Data RRD-GSSSD $R$ 88-84, Gas-Water System. Ice Solubility in Nitrogen and Air Within the Temperature Range from $-50^{\circ} \mathrm{C}$ to $-2^{\circ} \mathrm{C}$ and Pressure Range from 0.2 MPa to $61 \mathrm{MPa}$ (VNITS SMV of Gosstandart, Moscow, 1984) (in Russian)

6. V.G. Beketov, V.A. Rabinovich, M.D. Rogovin, Tables of Reference Data GSSSD 168-94. Moist Nitrogen. Thermodynamic Properties Within the Temperature Range from 200 to $400 \mathrm{~K}$, Pressure Range from 0.1 to $10 \mathrm{MPa}$ and Relative Humidity Range from 0.2 to 1.0 (VNITS SMV of Gosstandart, Moscow, 1994). BibBook

7. O.I. Gudkov, N.I. Dubovikov, O.A. Podmurnaya, Tables of Reference Data GSSSD 207-2004. Moist Nitrogen. Enhancement Factors Within the Temperature Range from 283 to 323 K, Pressure Range from 0.1 to $10 \mathrm{MPa}$ (VNITS SMV of Gosstandart, Moscow, 2004). in Russian

8. R. Hardy, in Paper and abstract from the third international symposium on humidity and moisture, vol. 1 (Teddington, UK, National Physical Laboratory, 1998), pp. 214-222

9. O.A. Podmurnaya, A.F. Vinge, State Primary Standard of Humidity Unit of Gases. East-Siberian Branch VNIIFTRI Report to the Russian Federal Agency on Technical Regulating and Metrology (2010), pp. 1-51

10. I.A. Sokov, N.A. Dubovikov, O.A. Podmurnaya, State Primary Standard of a Relative Humidity Unit of Gases. East-Siberian Branch VNIIFTRI Report to the USSR State Committee of Standards (1985), pp. $1-60$

11. GOST 8.547-1986, State System for Ensuring the Uniformity of Measurements. State Primary Standard and State Verification Schedule for Means Measuring Relative Humidity of Gases (Isdatelstvo standartov, Moscow, 1986), pp. 1-4

12. GOST 8.547-2009, State System for Ensuring the Uniformity of Measurements. State Primary Standard and State Verification Schedule for Means Measuring Relative Humidity of Gases (Standartinform, Moscow, 2010), pp. 1-7 